\title{
Competência metalinguística antes da escolarização formal
}

\section{Metalinguistic competencies before literacy}

\author{
Antonio Roazzi ${ }^{1}$ \\ Rafaella Asfora ${ }^{2}$ \\ Bianca Queiroga ${ }^{3}$ \\ Maria da Graça Dias ${ }^{4}$
}

\begin{abstract}
RESUMO
A proposta do artigo é explorar a relação entre habilidades linguísticas e metalinguísticas, tanto antes da escolarização formal como nos primeiros anos escolares, e discutir o conceito de metalinguagem sob a perspectiva de diferentes disciplinas: a linguística e a psicologia. No que se refere à relação entre o conhecimento linguístico e metalinguístico, discute-se a diferenciação de habilidades decorrentes do uso da linguagem e habilidades de reflexão consciente sobre as estruturas e funcionamento da linguagem. Apesar dessa diferenciação, o estudo ressalta a importância do desenvolvimento linguístico para o desenvolvimento das competências metalinguísticas que serão requeridas durante a aprendizagem formal da leitura e escrita. Quanto às diferentes perspectivas de estudo da metalinguagem, o artigo explica que enquanto a linguística está interessada em detectar palavras que se referem exclusivamente a outras palavras ou classes de significados, tendo como base o significante já existente no uso da língua; a psicologia busca a compreensão da atividade metalinguística, sob o ponto de vista do sujeito, através da manipulação reflexiva da linguagem. Por fim, ressalta-se a importância de tais aquisições para o sucesso na aprendizagem nos anos iniciais da alfabetização.

Palavras-chave: habilidades linguísticas; desenvolvimento metalinguístico; alfabetização.
\end{abstract}

1 Doutor em Psicologia do Desenvolvimento pela Universidade de Oxford. Professor titular da Universidade Federal de Pernambuco - Brasil, roazzi@gmail.com.

2 Doutora em Psicologia Cognitiva pela Universidade Federal de Pernambuco. Professora da Universidade Federal de Pernambuco - Brasil, rafaellaasfora@gmail.com.

3 Doutora em Psicologia Cognitiva pela Universidade Federal de Pernambuco. Professora da Universidade Federal de Pernambuco - Brasil., queiroga.bianca@gmail.com.

4 Doutora em Psicologia do Desenvolvimento pela Universidade de Oxford. Professora da Universidade Federal de Pernambuco - Brasil, gracabbdias@gmail.com. 


\begin{abstract}
This paper purpose is to explore the relationship between linguistic and metalinguistic skills before formal schooling and in the early school years and discuss the concept of metalanguage from the perspective of different disciplines: linguistics and psychology. Regarding the relationship between linguistic and metalinguistic knowledge, we discuss the distinction of skills resulting from the use of language and skills of conscious reflection about the structures and functioning of language. In spite of this distinction, the study emphasizes the importance of the linguistic development for the improvement of the metalinguistic competence that will be requested during the formal apprenticeship of reading and spelling. As for the different perspectives of metalanguage studies, this article explains that while linguistics is interested in detecting words that refer exclusively to other words or classes of meanings taking the already existent significant as a base in the language use; Psychology looks for the understanding of the metalinguistic activity, from the subject's point of view, through the reflexive manipulation of the language. Finally, the importance of such acquisitions is emphasized for the success in learning during the literacy initial years.
\end{abstract}

Keywords: linguistic skills; metalinguistic development; literacy.

\title{
Competência metalinguística antes da escolarização formal
}

Durante os anos que antecedem o período de alfabetização formal, a competência linguística de uma criança se enriquece tanto do ponto de vista lexical quanto sintático, possibilitando-lhe uma maior eficiência comunicativa. Essa competência que, em princípio, parece um processo não "consciente", aos poucos passa a revelar a existência de uma sensibilidade metalinguística para compreender mensagens ambíguas, para avaliar a aceitabilidade linguística de frases verificáveis em um contexto como descrições, observações, entre outras. Sobre isso existem inúmeras evidências de pesquisas que reconhecem que a criança, antes da escolarização formal, procura, ativamente, compreender a natureza da linguagem que se fala em sua volta e que, na tentativa de compreendê-la, formula hipóteses, procura regularidades, submete suas previsões à verificação e constrói uma gramática própria, que não é uma simples cópia do modelo adulto, mas uma criação bem original.

Assim, quando a criança inicia o processo de escolarização formal (alfabetização) tem acumulado um notável conhecimento da própria língua, possuindo um saber linguístico decorrente do uso que faz dessa língua em todas as suas ações comunicativas do dia a dia (e.g., COHEN; GILABERT, 1986; FERREIRO; 
TEBEROSKY, 1979; FORMISANO; ZUCCHERMAGLIO, 1992; GOODMAN, 1990, 1991). Um bom exemplo disso seria a escolha e organização de palavras na construção de frases de acordo com regras bem precisas, que possibilitam à criança falar e ser entendida em diversos contextos comunicativos.

Entretanto, do ponto de vista psicolinguístico, não seria lícito identificar essa execução como sendo uma competência efetiva a respeito da própria língua. Essa distinção entre competência e execução, que se torna mais clara na psicolinguística a partir das ideias de Chomsky e que se observa também nos próprios fundamentos da teoria piagetiana da inteligência, não pode ser negligenciada no contexto escolar. Piaget ressaltou em sua teoria que a criança busca o conhecimento se posicionando ativamente frente ao mundo no qual está inserida, procurando compreendê-lo. Em outras palavras, para Piaget, a criança atua, interage com objetos e pessoas e, a partir desta interação ativa, aprende.

Dessa forma, não é possível pensar no processo de aprendizagem da modalidade escrita, que se inicia na escola sem considerar o conhecimento linguístico anterior das crianças. Além disso, na atualidade, as crianças interagem continuamente com esta modalidade em seu cotidiano, seja através do computador, de mensagens publicitárias, da televisão, de rótulos e embalagens de produtos que consomem, entre outros, e as mesmas não reagem passivamente a toda essa gama de estímulos, muito pelo contrário, os estímulos visuais são transformados ativamente por elas através dos esquemas de assimilação que resultam em interpretações próprias.

Assim, o construto Piagetiano, tomado de modo específico para explicar a aprendizagem da língua escrita, não pode ser visto de forma dissociada da compreensão da dimensão sócio-histórica de tal processo. Sobre isso, Soares (1998) ressalta a importância de se aprender e ensinar a ler e escrever nos contextos das práticas sociais de leitura e escrita, fazendo referência aos conceitos de alfabetização e letramento.

Outro aspecto a ser ressaltado é que os processos de assimilação não são iguais para todos. Isto significa que no centro do processo de aprendizagem está a criança com o seu saber linguístico acumulado, que é diferente do saber de outra criança. Gardner (1991) aponta na mesma direção quando faz um alerta para que estudiosos e interessados na educação desconfiem dos estereótipos e dos scripts que levam a considerar as crianças que iniciam a escola como dotadas de uma mesma inteligência, de conhecimentos e habilidades mais ou menos similares, em um processo de homogeneização, pois o autor também defende que a aprendizagem não ocorre para todos da mesma forma. Como sublinhado por Gardner (1991), existem várias formas de adquirir e de representar os conhecimentos que precisam ser consideradas do ponto de vista pedagógico. Às vezes as crianças são incapazes de realizar com sucesso provas de 
competências comuns, mas quando as mesmas são apresentadas novamente, considerando-se o seu conhecimento prévio, revelam uma significativa capacidade de dominar e compreender.

Hamiton, Barton e Ivanic (1994) descrevem várias situações de aprendizagem da leitura e escrita (literacy) ${ }^{5}$ e suas práticas oferecendo um panorama de inúmeros contextos de uso no qual a escrita desempenha um papel relevante na sociedade atual. Assim, investigando a organização social do processo de ler e escrever, Hamilton et al. descrevem a existência de formas variadas de "literacy". De fato, os indivíduos apresentam experiências específicas, objetivos e intenções diferentes para a leitura e a escrita. Existem mundos distintos dos adultos e das crianças, das pessoas que falam várias línguas, dos homens e das mulheres. Existem também vários mundos públicos da "literacy", definidos pelas instituições sociais, incluindo escolas, locais de trabalho e outras instituições. Estes mundos ou microculturas não dizem respeito somente às letras e palavras, à leitura e escrita, aos artigos e monitores de computador, mas, sobretudo, às várias práticas culturais. Viver no espaço simbólico de uma cultura letrada significa aprender tais práticas, aprender como participar de jogos linguísticos orais e escritos dessa cultura. É nesse contexto que a "literacy", tomada como dimensão de mundo pessoal, se funde com a "literacy" como espaço simbólico de uma cultura no processo de construção da própria identidade da criança. De fato, é primariamente nesses mundos, ou melhor, nas microculturas do dia a dia que a criança, construindo, elaborando e compartilhando significados com outros se serve da linguagem, se apropria cada vez mais, a usa (WITTGENSTEIN, 1953) e conhece e incorpora a mesma construindo o próprio self (BRUNER, 1990).

Assim, o respeito à diversidade linguística, cultural, bem como o conhecimento das competências cognitivo e linguísticas individuais, constitui um grande desafio para a educação contemporânea. Com relação a este último aspecto, desde a segunda metade dos anos 70, em uma variedade de disciplinas que tratam da língua, nota-se um forte interesse para aqueles aspectos dos processos psicológicos que denotam a capacidade de refletir sobre as estruturas e sobre o funcionamento da linguagem, processos de formas variadas, denominadas como capacidades, habilidades metalinguísticas, consciência ou consciência metalinguística.

A amplitude dessas flutuações terminológicas, por sua vez, é indicativa das variedades de abordagens e perspectivas que têm tratado a dimensão metalinguística nas últimas décadas.

5 A palavra inglesa "literacy" pode ser traduzida como alfabetização (ou capacidade de ler e escrever, conhecimento específico em determinada área, hábito de leitura). Entretanto o termo alfabetização não possui a riqueza polissemântica do termo em inglês, visto que o termo pode se referir tanto à condição como ao processo de familiaridade com a língua escrita. 


\section{Metalinguagem: da linguística à psicologia}

A criação do termo metalinguagem deriva da linguística. Jakobson (1963) considera, entre as funções secundárias da linguagem, exatamente a função metalinguística como a atividade que consiste em falar da própria palavra, e assume, portanto, a própria linguagem como conteúdo.

Na mesma perspectiva, Benveniste (1974) define a capacidade metalinguística como a possibilidade de fazermos, nós mesmos, levantamentos acerca da linguagem, de abstrairmos sobre ela, de contemplá-la enquanto fazemos uso dela em nosso raciocínio e em nossas observações.

Entretanto, como bem colocado por Gombert (1992), a atitude e a preocupação do linguista, em relação às dimensões metalinguísticas, são diferentes em relação às preocupações implícitas a uma perspectiva psicológica do termo.

O linguista está interessado em detectar, como exemplos de metalinguagem, palavras que se referem exclusivamente a outras palavras, classes de significados criadas tendo como base significantes já existentes no uso da língua. É o caso de cada terminologia linguística, independentemente de ser antiga ou nova. Assim, por exemplo, as palavras sintaxe, semântica, fonema, verbo, entre outras, estão relacionadas a exemplos de unidades linguísticas reunidas em categorias mais amplas de acordo com as dimensões como, por exemplo, a ordem das palavras, o significado etc. Assim, enquanto a palavra "gato", por si só, se conecta a um exemplar de gato, tendo como base uma classificação do mundo extralinguístico, a expressão "o substantivo gato" se conecta a uma classificação que é puramente intralinguística. A palavra substantivo é uma palavra que reporta a linguagem a si mesma, e é, portanto, definível como uma marca linguística com um valor autorreferencial.

Em uma perspectiva diferente, quando a psicologia procura traços de uma determinada atividade metalinguística, busca enxergar as coisas pela vertente do sujeito humano e irá se expressar através de um léxico que é organizado por palavras como: capacidade, condutas, atitudes, processos, entre outros. Nesta perspectiva, pode-se até prescindir da presença dos marcadores metalinguísticos próprios da linguística, mas se consegue detectar outras condutas que possibilitam legitimamente pensar em uma manipulação reflexiva da linguagem. Assim, entre a atitude da linguística e da psicologia existe uma complementaridade; enquanto a primeira aborda os fatos da língua do ponto de vista do objeto-código e detecta, desta forma, as unidades pertinentes, a segunda examina os fatos da língua, do ponto de vista do ser humano em ação, tendo como base os processos psicológicos que podem ou não ter uma expressão verbal. 
O ponto de vista psicológico auxilia o linguista a restituir a linguagem para quem a elabora, o ser humano (HAGËGE, 1993). Por sua vez, o ponto de vista do linguista ajuda o psicólogo a compreender como uma atividade cognitiva de reflexão sobre determinados usos da língua carece de uma forma mais ou menos pertinente de determinadas unidades de natureza linguística.

\section{Metalinguagem na perspectiva da psicologia}

A natureza das questões relacionadas ao desenvolvimento metalinguístico explica de forma clara a pluralidade de investigações produzidas nas últimas três décadas. O primeiro problema diz respeito à determinação de alguns critérios que possibilitem reconhecer o surgimento de comportamentos metalinguísticos significativos. Em outras palavras, o uso do prefixo "meta-" do adjetivo metalinguístico, que nos remete a algo que vai "além", precisa ser justificado por elementos suficientemente distintos da utilização da língua em termos de produção e compreensão, de tal forma, que quando estes elementos estiverem presentes, seja possível identificá-los com clareza.

Um segundo aspecto é que, em uma perspectiva do desenvolvimento cognitivo, é necessário detectar mudanças qualitativas e quantitativas que possam distinguir as capacidades metalinguísticas emergentes de crianças pequenas (antes dos 5 anos de idade), de pré-adolescentes, de adolescentes ou até de adultos escolarizados. Do ponto de vista das diferenças qualitativas, Flores (2008) argumenta que os adultos, mesmo sem terem o conhecimento explícito dos subprocessos envolvidos na compreensão e produção linguísticas, ou não estejam conscientemente preocupados, podem, portanto, acessá-los no momento em que desejarem.

Um terceiro e último aspecto importante refere-se à necessidade de esclarecer se é adequado falar em capacidades metalinguísticas (compreendidas de maneira global) ou de habilidades específicas.

A esses problemas podem ser adicionadas, ainda, outras questões de cunho evolutivo, oriundas da relação entre o desenvolvimento metalinguístico de um lado, e, por outro lado, o desenvolvimento de outras competências relacionadas com a linguagem: o desenvolvimento cognitivo, o desenvolvimento da leitura e escrita e dos conceitos gramaticais.

Uma contribuição decisiva acerca dessas questões foi oferecida por Tunmer, Pratt e Herriman (1984), que definem a consciência metalinguística como uma capacidade de refletir e manipular as características da linguagem, tratando-a 
como um objeto de pensamento por si só, o que se contrapõe à simples utilização do sistema linguístico para compreender e produzir frases.

Tunmer e Bowey (1984, p. 148) acrescentam que habilidades linguísticas e metalinguísticas são processos diferentes, uma vez que a atividade metalinguística

refere-se à habilidade de refletir sobre e de manipular as características estruturais da linguagem falada [ou escrita], tratandoa, em si mesma, como um objeto de pensamento, em oposição ao uso do sistema para compreender e produzir sentenças.

Para Tunmer, Pratt e Herriman (1984), a metalinguagem estaria inserida na categoria geral da metacognição de forma similar à metamemória, à metaaprendizagem, à meta-atenção, à metacognição social, incluindo, por sua vez, quatro áreas específicas: consciência fonológica, consciência da palavra, consciência sintática e a consciência pragmática.

Para os autores, do ponto de vista evolutivo, as várias habilidades metalinguísticas emergeriam concomitantemente, mas seria a capacidade de ir além da compreensão e produção, assumindo a linguagem intencionalmente como objeto do pensamento, que iria revelar o desenvolvimento de tais habilidades. Sobre isso, Tunmer, Pratt e Herriman (1984) apontam a existência de dois tipos de consciência: a consciência intuitiva dos propósitos das declarações e a consciência das características estruturais dos enunciados. A primeira refere-se à capacidade de uma criança, nas fases iniciais de desenvolvimento da linguagem, em efetuar modificações que apresentam um valor adaptativo específico. A segunda não seria concebível antes da consolidação de certas estruturas lexicais e sintáticas básicas, e antes da emergência de um controle metacognitivo de natureza transversal, que engloba todos os aspectos da atividade mental.

Pesquisas empíricas têm confirmado o desenvolvimento espontâneo dos processos de análise que se aplicam à língua falada, anteriores e independentes da influência do contato direto com o sistema da escrita. Assim, o surgimento da consciência metalinguística ocorreria durante as primeiras tentativas da criança em realizar manipulações estruturais na língua falada. Estudos realizados em diferentes línguas têm revelado que a criança é capaz de elaborar um código pessoal de interpretação das correspondências grafema-fonema antes que a escola ensine os princípios convencionais (COHEN; GILABERT, 1986; FORMISANO; ZUCCHERMAGLIO, 1992; GOODMAN, 1990, 1991). O grau de articulação 
deste código parece se desenvolver de acordo com uma sucessão de etapas cuja regularidade não seria dependente das peculiaridades das diferentes línguas. Esta constatação confirmaria, de certa forma, a tese segundo a qual a aquisição da leitura e escrita no início da escolarização não pode ser considerada o principal fator no desenvolvimento das habilidades metalinguísticas, mas uma consolidação e expansão dos processos metacognitivos já em andamento.

Uma perspectiva diferente sobre habilidades metalinguísticas é fornecida por Feldman (1991, 2000), que propõe a existência de metalinguagem oral admitindo a existência de um nível meta também em populações nas quais prevalece a cultura oral. Trata-se de tipologias textuais orais que se diferenciam da linguagem cotidiana e que requerem certa habilidade por parte do seu executor. Esses mesmos gêneros na nossa cultura ocidental são geralmente representados na escrita e possuem características similares àquelas que Olson (1991) considera próprias de uma cultura alfabetizada. É o caso interessante da poesia Wana (população da indonésia) o kiyori, um gênero oral no qual o destinatário é chamado a interpretar a sucessiva produção de um texto propositalmente ambíguo. A pesquisadora considera que a capacidade de refletir sobre um texto pode não requerer a alfabetização, como no caso dos Wana, ou dos Ilongot das Filipinas. Estes últimos possuem, por exemplo, o gênero oral purung, utilizados nas disputas públicas relacionadas a questões políticas e de justiça, nas quais uma ênfase especial é posta sobre os aspectos locutórios do discurso, sobre as modalidades interpretativas efetuadas, observação sobre os estados epistêmicos dos interlocutores etc.

No mesmo sentido, no Brasil existe um fenômeno bem interessante que é o uso do repente nas regiões do nordeste, que foi estudado do ponto de vista cognitivo por Roazzi e colaboradores (ROAZZI; DOWKER; BRYANT, 1991; ROAZZI; OLIVEIRA; BRYANT; DOWKER, 1994). Os "repentistas", "violeiros" ou "cantadores", como em geral são chamados, podem ser definidos como poetas de rua que compõem poemas a partir de um tema qualquer dado, seguindo formas e regras poéticas características muito sofisticadas. Estes cantadores se apresentam individualmente ou em duplas, geralmente em festas populares, quando realizam competições ou "pelejas" demonstrando habilidade e destreza na poesia. Desta forma, sujeitos de populações caracterizadas por um tipo de "oralidade primária", próprias das culturas não alfabetizadas, podem interpretar e negociar os significados transmitidos até de forma bastante sofisticadas, denotando um nível de metalinguagem caracterizado pela oralidade.

Outro exemplo de influência da oralidade sobre a metalinguagem em diferentes condições de vida, estudado com frequência, tem sido o fenômeno do bilinguismo. De um modo geral, a análise de tarefas metalinguísticas tem sido muito interessante e útil para identificar diferenças qualitativas em grupos de 
pessoas que tiveram condições de desenvolvimento linguístico diferentes, como é o caso do desenvolvimento bilíngue e monolíngue. Os principais resultados das pesquisas revelam que o bilinguismo favorece o desenvolvimento da consciência metalinguística, inclusive quando se fez o controle de outras variáveis linguísticas e cognitivas (BALKAN, 1970; BEN-ZEEV, 1972, 1977a 1977B; CUMMINS, 1978; CUMMINS; GULUTSAN, 1974; HAKUTA, 1986; HAKUTA; DIAZ, 1984; YELLAND; POLLARD; MERCURY, 1993).

Em obras mais recentes, Bialystok e colaboradores (2003, 2004, 2006) defendem que a vantagem de bilíngues em relação às habilidades metalinguísticas refere-se às tarefas em que é necessário o uso de controle inibitório, sobretudo em situações em que haja informações conflitantes.

Assim, as evidências das pesquisas descritas acima oferecem suporte para uma visão mais geral da metalinguagem no sentido psicológico do termo, especialmente no que concerne à descrição de habilidades que se desenvolvem antes ou independente das práticas formais de alfabetização, sendo inegável a importância destas para o desenvolvimento cognitivo dos indivíduos.

\section{Considerações finais e implicações educacionais}

Como foi apontado, as crianças aprendem as peculiaridades da linguagem através do uso que fazem desta em diferentes experiências cotidianas: nas perguntas, nas respostas, nas discussões, nas histórias, nos diálogos, enfim, nas mais diversas formas de interação social dentro e fora do contexto escolar. A partir deste conhecimento, formularão as primeiras hipóteses sobre a modalidade escrita, quando expostas ao aprendizado formal da alfabetização ou mesmo quando viverem as primeiras experiências de uso social da escrita (letramento).

Nesse sentido, a escola necessita acompanhar o desenvolvimento da linguagem especialmente na primeira infância, visto que este desenvolvimento possibilitará novas aprendizagens futuras, especialmente a aprendizagem da leitura e escrita. A este propósito, Vygotsky (1987), argumentando sobre as fases de desenvolvimento do pensamento e da linguagem, alerta que na criança, já por volta dos dois anos de idade, a vontade de conquistar a linguagem produz uma mudança significativa em sua interação com o ambiente, que constitui uma das grandes descobertas desta fase: a descoberta que cada coisa possui um nome. Antes deste momento crítico, a criança seria capaz de reconhecer um pequeno número de palavras que substituem objetos, pessoas, ações, estados ou desejos. A partir do momento que a criança descobre que tudo tem um nome, cada novo 
objeto que surge representa um problema que necessita ser resolvido. Quando the falta a palavra para nomear este novo objeto, a criança recorre ao adulto. Esses significados básicos de palavras, assim adquiridos, funcionarão como embriões para a formação de novos e mais complexos conceitos linguísticos.

Assim, para que o conhecimento linguístico da criança seja aproveitado (e respeitado), é importante que a escola evite trabalhar com o código escrito através de atividades mecânicas, ritualísticas ou convencionais, sem considerar os conceitos e simbolismos já adquiridos, uma vez que não considerar os conhecimentos prévios levaria a criança a ignorar tudo o que havia construído até aquele momento. Pelo contrário, se considerarmos o longo percurso cognitivo percorrido pela criança, a escrita alfabética é para ela um ponto de chegada, que ampliará suas aquisições anteriores, e não um ponto de partida para uma nova aprendizagem.

Ainda nesse sentido, Vygotsky (1984) acrescenta que a escrita deve ser apresentada à criança como uma tarefa válida e relevante para a vida, como uma forma nova e completa de linguagem, e não como um hábito de mãos e dedos. É, pois, na perspectiva do uso que se propõe a aquisição de uma nova habilidade.

Assim, é possível defender que o desenvolvimento das habilidades metalinguísticas seja privilegiado na escola a partir das experiências linguísticas anteriores da criança, pois, como defende Vygotsky (1987), para a criança é quase impossível se tornar consciente de uma habilidade antes de tê-la adquirido. Neste sentido, sendo uma usuária competente de sua língua, será mais fácil refletir de maneira consciente sobre essa língua.

Além disso, após o ingresso na escolarização formal, a escola necessita continuar a proporcionar às crianças a possibilidade de brincar com a língua, recuperando e fortalecendo a dimensão oral, interativa e comunicativa da linguagem, que muitas vezes é posta de lado na fase da alfabetização em prol de formas de experiências mais tradicionais e formais. Proporcionar o devido espaço a uma "didática da metalinguagem" significa estruturar caminhos e formas pedagógicas que possibilitem que as crianças continuem se relacionando com a linguagem como um conteúdo que fala por si só, como um objeto com o qual pode brincar e se deleitar. Podem ser tomados como exemplos de tais práticas o uso de linguagens poéticas, jogos linguísticos, práticas narrativas, metadis$\operatorname{cursos}^{6}$, entre outros.

6 Por metadiscurso entende-se aquelas práticas comunicacionais através das quais se faz referências explícitas à linguagem oral (e.g., esclarecendo o que tem sido dito, explicando um conteúdo, interpretando um ato linguístico etc.) e à linguagem escrita. Ver também as formas humorísticas, expressões com duplo sentido e ironia. 
Concluindo, quando se fala de relações entre leitura-escrita e desenvolvimento metalinguístico é necessário distinguir entre componentes e fases de ambos os processos. A presença objetiva de códigos em forma escrita no ambiente social da criança, mediada pela disponibilidade do adulto que aponta o seu funcionamento e uso, representa, com toda certeza, um ponto de partida para uma série de atividades metalinguísticas que podem anteceder substancialmente o contato com o processo de alfabetização formal ao ingressar na escola. Entretanto, este ponto de partida não substitui o processo de elaboração em si mesmo, que permanece subjetivo e suscetível a amplas variações em função das possíveis interações que se estabelecem entre a criança, os objetos e o adulto. Assim, o processo de aquisição da leitura e da escrita no início da escolarização formal não pode ser considerado como o fator principal no desenvolvimento de capacidades metalinguísticas, mas uma consolidação e uma expansão dos processos metacognitivos já desencadeados em fases anteriores.

\section{REFERÊNCIAS}

BALKAN, L. Les effets du bilinguisme Franças-Anglais sur les aptitudes intellectuelles. Brussels: Aimav, 1970.

BENVENISTE, E. Problémes de linguistique génerale II. Paris: Gallimard, 1974.

BEN-ZEEV, S. Mechanisms by which childhood bilingualism affects understanding of language and cognitive structures. In: HORNBY, P. A. (Ed.). Bilingualism: Psychological, social, and educational implications. New York: Academic, 1977a.

. The effect of bilingualism in children from Spanish-English low economic neighbourhoods on cognitive development and cognitive strategy. Working Papers on Bilingualism, n. 14, p. 83-122, 1977 b.

. The Influence of bilingualism on cognitive development and cognitive strategy. Unpublished PhD dissertation. University of Chicago, 1972.

BIALYSTOK, E. Bilinguism in Development: Language, Literacy \& Cognition. 5. ed. Nova York: Cambridge University Press, 2006. 
BIALYSTOK, E.; MAJUMDER, M. Developing phonological awareness: is there a bilingual advantage? Applied Psycholinguistics, n. 24, p. 27-44, 2003.

BIALYSTOK, E.; MARTIN, M. M. Attention and Inhibition in bilingual children: Evidence from the dimensional change card sort task. Developmental Science, v. 7, n. 3, p. 325-339, jun. 2004.

BRUNER, J. Acts of Meanings. Cambridge: Harvard University Press, 1990.

COHEN, R.; GILABERT, H. Dècouverte et apprentissage du langange ecrit avant six ans. Paris: PUF, 1986.

CUMMINS, J. Bilingualism and the development of metalinguistic awareness. Journal of Cross-Cultural Pschology, n. 9, p. 139-149, 1978.

CUMMINS, J.; GULUTSAN, M. Some effects of bilingualism on cognitive functioning. In: CAREY, S. T. (Ed.). Bilingualism, Biculturalism and Education. Edmonton: University of Alberta Press, 1974.

FELDMAN, C. Oral metalanguage. In: OLSON, D. R.; TORRANCE, N. (Eds.). Literacy and orality. Cambridge: Cambridge University Press, 1991.

. The sociability of meaning: Olson's interpretative community. In: ASTINGTON, J. W. (Ed.). Minds in the making. Oxford: Blackwell, 2000. p. $17-28$.

FERREIRO, E.; TEBEROSKY, A. A. Psicogênese da língua escrita. Porto Alegre: Ed. Artmed, 1979.

FLORES, O. Compreensão/interpretação de implícitos e aprendizagem da leitura. Letras de Hoje, v. 43, n. 2, p. 40-46, 2008.

FORMISANO, M.; ZUCCHERMAGLIO, C. Guida alla lingua scritta. Roma: Editori Riuniti, 1992.

GARDNER, H. The Unschooled Mind: How children think and how schools should teach. New York: Basic Books, 1991.

GOMBERT, J. E. Metalinguistc Development. New York, London: HarvesterWheatsheaf, 1992.

GOODMAN, Y. (Ed.). How children construct literacy. Newark, DE: International Reading Association, 1990. 
. Las raíces de la alfabetización. Infancia y Aprendizaje, número especial, p. 29-42, 1991.

HAGÈGE, C. The language builder: An essay on the human signature in linguistic morphogenesis. Amsterdam: John Benjamins, 1993.

HAKUTA, K. Mirror of language. New York: Basic Books, 1986.

HAKUTA, K.; DIAZ, R. M. The relationship between bilingualism and cognitive ability: A critical discussion and some new longitudinal data. In: NELSON, K. E. (Ed.). Children's language. Hillsdale, NJ: Erlbaum, 1984. v. 5.

HAMILTON, M.; BARTON, D.; IVANIC, R. (Eds.). Worlds of literacy. Ontario Institute for Studies in Education. Philadelphia \& Adelaide: Multilingual Matters, Toronto, Clevendon, 1994.

JAKOBSON, R. Essais de Linguistique Générale. Paris: Minuit, 1963.

OLSON, D. R. Literacy as metalinguistic activity. In: OLSON, D. R.; TORRANCE, N. (Eds.). Literacy and orality. Cambridge: Cambridge University Press, 1991. p. 251-270.

ROAZZI, A.; DOWKER, A. R. A.; BRYANT, P. E. A Arte do Repente e as Habilidades Lingüísticas. Revista Brasileira de Estudos Pedagógicos, n. 72, p. 291-317, 1991.

ROAZZI, A.; OLIVEIRA, G. G. de; BRYANT, P. E.; DOWKER, A. As habilidades lingüísticas dos repentistas e sua relação com o nível de consciência fonológica. Cadernos de Estudos Linguísticos, n. 26, p. 135-158, 1994.

SOARES, M. B. Letramento: um tema em três gêneros. Belo Horizonte: Autêntica, 1998.

TUNMER, E.; BOWEY, J. Metalinguistic awareness and reading acquisition. In: TUNMER, W. E.; PRATT, C.; HERRIMAN, M. L. (Eds.). Metalinguistic awareness in children: theory, research, and implications. New York: SpringerVerlag, 1984.

TUNMER, E.; PRATT, C.; HERRIMAN, M. Metalinguistic Awareness in Children. Theory, Research and Implications. Berlin: Springer, 1984.

VYGOTSKY, L. A formação social da mente. São Paulo: Martins Fontes, 1984. 
. Pensamento e linguagem. São Paulo: Martins Fontes, 1987.

WITTGENSTEIN, L. Philosophical investigations. Oxford: Basil Blackwell, 1953.

YELLAND, G.; POLLARD, J.; MERCURY, A. The metalinguistic benefits of limited contact with a second language. Applied Psycholinguistics, n. 14, p. 423-444, 1993.

Texto recebido em 29 de junho de 2010 .

Texto aprovado em 19 de julho de 2010. 